\title{
Hydroponics as an innovative technique for lettuce production in greenhouse environment
}

\author{
Abdul Qadeer ${ }^{1}$, Zia-Ul-Haq ${ }^{1 *}$, Shahid Javed Butt ${ }^{2}$, Hamza Muneer \\ Asam $^{1}$, Talha Mehmood ${ }^{1}$, Muhammad Kazim Nawaz ${ }^{1}$ and Sohail Raza \\ Haidree $^{1}$ \\ 1. Faculty of Agricultural Engineering and Technology, PMAS-Arid Agriculture University, Rawalpindi, Pakistan \\ 2. Institute of Hydroponic Agriculture, PMAS-Arid Agriculture University, Rawalpindi, Pakistan \\ *Corresponding author's email: ziaulhaquaf@gmail.com
}

\section{Citation}

Abdul Qadeer, Zia-Ul-Haq, Shahid Javed Butt, Hamza Muneer Asam, Talha Mehmood, Muhammad Kazim Nawaz and Sohail Raza Haidree. Hydroponics as an innovative technique for lettuce production in greenhouse environment. Pure and Applied Biology. Vol. 9, Issue 1, pp20-26. http://dx.doi.org/10.19045/bspab.2020.90130

\begin{tabular}{llll}
\hline \hline Received: 24/11/2019 & Revised: 24/01/2020 & Accepted: 27/01/2020 & Online First: 07/02/2020 \\
\hline
\end{tabular}

\section{Abstract}

Lettuce (Lactuca sativa) is an appetizing top leafy vegetable used as salad consumed all over the world due to a good source of vitamins and minerals. In Pakistan conventional lettuce production in soil (geoponics) is insufficient to meet the market demand round the year. However, customers demands for fresh lettuce during offseason. In this scenario, alternative farming practices like nutrient film technique is only feasible and have great yield promise. Keeping in view the market demand of lettuce an experiment was conducted at Hydroponic Research Station Rawat, Institute of Hydroponic Agriculture, Pir Mehr Ali Shah Agriculture University Rawalpindi. Static hydroponic system was developed in the experiment and its comparison was made with the geoponics in the green house condition. Growth and yield parameters were recorded. Crop parameters including plant height, number of leaves per plant, length of leaf, breadth of leaf, and yield per plant in five treatments $\mathrm{T}_{1}$ (static pipe with $7.6 \mathrm{~cm}$ dia.), $\mathrm{T}_{2}$ (static pipe with $10.1 \mathrm{~cm} \mathrm{dia.)}, \mathrm{T}_{3}$ (static tray with $8.8 \mathrm{~cm}$ width), $\mathrm{T}_{4}$ (static tray with $12.5 \mathrm{~cm}$ width) and $\mathrm{T}_{5}$ (Geoponics) were measured. To take the average data five plants were selected from each treatment. The data were statistically analyzed in Completely Randomized Design (CRD) at $5 \%$ level of probability. Yield per plant in treatments $\mathrm{T}_{1}, \mathrm{~T}_{2}, \mathrm{~T}_{3}$, $\mathrm{T}_{4}, \mathrm{~T}_{5}$, was observed $190.80,245.80,176,213.40$ and 150.80 respectively. Highest yield per plant (245.80) was recorded in treatment $T_{2}$ while the least yield per plant (150.80) observed in treatment $T_{5}$.

Keywords: Geoponics; Lettuce; Static hydroponic system

\section{Introduction}

The huge increase in population and alarming rate of water shortage will cause more stress on agriculture resources thus there is a dire need of alternative food production system. This need resource conservation, precision engineering and alternative food growing system to sustain agriculture in urban and water stressed environment. To reasonably feed the world's growing population, techniques for growing sufficient food have to evolve. Modification in growth medium is an alternative for sustainable production and to conserve fast depleting land and available water resources. In the present scenario, soil less cultivation might be commenced successfully and considered as alternative option for growing 
healthy food plants, crops, herbs, lettuce and vegetables [1]. Different techniques can be used to develop hydroponic system. To choose which technique is best depends mainly on the type of plant as well as the availability of growing space. Mostly these techniques are divided in two systems open and close. As these system types may similar in different features including design, they also have contrast that how they maintain the nutrient solution [2]. The different techniques used for growing plants without using soil called hydroponics or soilless culture. The techniques of soilless culture contain diverse system, which fully depends on water and nutrients only (e.g., nutrient film technique or NFT) as compared to those based on artificial mixes that include many properties of soil [3]. In the present experiment NFT system has been developed by using two types of channels PVC pipes and Flat trays made by galvanized steel. NFT technique has been used in this experiment by using static pipes and trays. In static NFT system there is no recirculation of water in the channels. In this system water retains in the channel and has been changed manually after every week.

Lettuce has been successfully grown in static nutrient film technique. Lettuce crop is easily grown in static nutrient film technique with better production. Lettuce may be grown with a single application of water and nutrients. Electricity and pumps are not required in static nutrient film technique. Only single air pump is required to provide oxygen to the plants. The additional production costs and complexities related with aeration and water circulation in other re-circulating hydroponic systems are avoided by this method [4]. Lettuce is mostly grown vegetable crop in hydroponics as customers want more health and diversity in their diets, the amount and variety of leafy greens and herbs desired by Americans has risen. Consumption on the basis of leaf lettuce disappearance per capita improved by 2014. Greens and herbs can be cultivated and sold for distinct markets on a number of scales, from farmers to largescale wholesale business accounts. Western manufacturing areas dominate the production of wholesale lettuce. While smaller scale wholesale production could be investigated by Kentucky manufacturers, possibilities for hydroponic greens are most probable to come from direct marketing to customers. Proper handling methods and other aspects of food safety are essential elements for the successful marketing of lettuce as well as other greens and herbs [5].

Conventional agricultural (geoponics) methods may cause many negative impacts on the environment. "Conventional has been historically defined as the practice of growing crops in soil, in the open air, with irrigation, and the active application of nutrients". Some of the negative impacts of traditional agriculture contain the more and incompetent use of water, more land requirements, higher amount of nutrients requirement, and soil erosion. The increase in growth of the world population require higher rate in the production of the food. To feed the world's growing population in a better way, innovative techniques for producing food have to be used [6]. There are several limitations in the conventional method (geoponics) of lettuce that only a single crop of lettuce can be grown in a given year. While much of the land used to produce lettuce is dedicated to warm season crops when lettuce is not in production. There is possibility that these crops have water and energy requirements that different from lettuce. Additionally, the hydroponic greenhouse system should be of commercial scale and was designed for optimum production [7]. This study was focus on introducing indigenously developed close hydroponic static nutrient film technique and its comparison was made with conventional 
soil system in greenhouse condition for lettuce production.

\section{Materials and methods}

\section{Study area}

The study for development of static hydroponic system and its comparison with the conventional geoponics was carried out at Hydroponic Research Station-Rawat, Institute of Hydroponic Agriculture, PMASArid Agriculture University Rawalpindi during 2018-19. Experimental area fall in the jurisdiction of district Rawalpindi, Pothwar region of North Punjab, Pakistan. For yearround supply of lettuce experiment was conducted in greenhouse condition.

\section{Treatments}

Five treatments were design in the experiment; $\mathrm{T}_{1}$ (static pipe with $7.6 \mathrm{~cm}$ dia.), $\mathrm{T}_{2}$ (static pipe with $10.1 \mathrm{~cm}$ dia.), $\mathrm{T}_{3}$ (static tray with $8.8 \mathrm{~cm}$ width), $\mathrm{T}_{4}$ (static tray with $12.5 \mathrm{~cm}$ width) and $\mathrm{T}_{5}$ (Geoponics). For comparative study of the different shapes of channels volume of water for $\mathrm{T}_{1}$ were kept equal to $\mathrm{T}_{4}$ and volume of water for $\mathrm{T}_{2}$ were kept equal to $\mathrm{T}_{4}$.

\section{Static hydroponic}

To achieve research objectives, static hydroponic system with different sizes of PVC pipes and galvanized steel trays were developed. Diameter of PVC pipes were 7.6 $\mathrm{cm} \& 10.1 \mathrm{~cm}$ while width of galvanized steel trays were $8.8 \mathrm{~cm} \mathrm{\&} 12.5 \mathrm{~cm}$. The length of each water channel was 3.6 meter for static hydroponic system. Plants grown in the water channels (PVC pipes \& galvanized steel trays) were fed with nutrient enrich solution. In this system there was no re-circulation of water so submersible water was not required in this system.

Air pumps were used in static hydroponic system having discharge rate of $2.5 \mathrm{~L} / \mathrm{min}$. Recommended irrigation water with $\mathrm{pH}$ (6-7) and EC (1.2-1.8) $\mathrm{dS} / \mathrm{m}$ for lettuce was provided to system [8]. Performance of static hydroponic system was monitored and its comparison was made with geoponics for lettuce production.

\section{Sowing of lettuce}

Rock-wool was used as a growing media for the growth of lettuce. Seeds were placed on rock-wool plug fitted into the net-pots. Rockwool plugs were washed out and sprayed using reverse osmosis (RO) water. Seed placed on the rock-wool with the help of a stick. Coco peat powder used to cover the seed surface which is helpful in keeping the rock-wool surface wet. Net-pots were used for sowing of lettuce plants are the plastic transparent cups. Using these cups as a netpots, were necessary to drill holes on all side wall and on the bottom of cup to provide proper ventilation and plant roots penetration.

The rock-wool was shaped according to the shape and size of plastic cup so that rockwool easily adjusted in the net-pots and used for the initial seedling growth of lettuce. After three days of sowing almost all the seed starts growing. Plastic sheet was removed from the net-pots and seedlings were irrigated with $\mathrm{RO}$ water daily until each plant attain at least two leaves. After achieving desire height about 2-3 leaves the nursery was shifted in the static hydroponic system under greenhouse environment.

\section{Geoponics}

To compare the performance of static hydroponic system with geoponics in green house conditions lettuce was also sown in border soil. To provide proper drainage holes were drilled at the bottom of each pots with the help of drill machine. The sowing of lettuce in border soil and in net-pots using rock-wool as a supporting media completed on the same day to evaluate the performance of lettuce in both static nutrient film technique and geoponics.

\section{Plant growth parameters}

Lettuce crop was grown in static hydroponic system and in geoponics. Crop parameters including plant height, number of leaves per 
plant, leaf length, leaf breadth, and yield per plant for five treatments $\left(\mathrm{T}_{1}, \mathrm{~T}_{2} \ldots . . \mathrm{T}_{5}\right)$ were measured.

\section{Statistical analysis}

Data measured in different treatments for various crop growth parameters were tatistically analyzed using software (Statistix 8.1) by following Completely Randomized Design (CRD). Results were compared using Least Significance Difference (LSD) at $5 \%$ level of Probability.

\section{Results and discussion}

The research was carried out for the comparison of static hydroponic system and geoponics. Various crop growth parameters measured during experiment were statistically analyzed by using Completely Randomize Design in Statistix 8.1 software. Mean tables including plant height, number of leaves per plant, leaf length, leaf breadth and yield per plant are represented in Table 1 to 5. The experiment was performed under greenhouse conditions so the external factors; sunlight, wind, rain, hail storm were not much adversely effective.

\section{Plant height (cm)}

Plant height (Table 1) was measured in static hydroponic system and in geoponics throughout the cropping cycle of lettuce. Average plant height in treatment $\mathrm{T}_{1}, \mathrm{~T}_{2}, \mathrm{~T}_{3}$, $\mathrm{T}_{4}$, and $\mathrm{T}_{5}$, was recorded $18.58,20.64,18.22$, 19.24 and $17.38 \mathrm{~cm}$ respectively. In all treatments the optimum plant height (20.64) was observed in treatment $T_{2}$ while the lowest plant height (17.38) was observed in treatment $\mathrm{T}_{5}$. Plant height in treatment $\mathrm{T}_{2}$ (20.64) is significantly different with all other treatments $\mathrm{T}_{1}$ (18.58), $\mathrm{T}_{3}$ (18.22), $\mathrm{T}_{4}$ (19.24) and $\mathrm{T}_{5}(17.38)$ respectively at $5 \%$ level of probability. Plant height in treatment $\mathrm{T}_{5}$ (17.38) is non-significantly differ with treatments $\mathrm{T}_{1}$ (18.58) and $\mathrm{T}_{3}(18.22)$ and significantly different with other treatments $\mathrm{T}_{2}$ (20.64) and $\mathrm{T}_{4}(19.24)$ at $5 \%$ level of probability.

Plant height is greater in static nutrient film technique than geoponics which is in accordance with the finding of scientist who stated that plants that are grown in soil tended to be less vigorous than those plants grown in static nutrient film technique (open hydroponic system) [6].

Table 1. Effect of various treatments on plant height

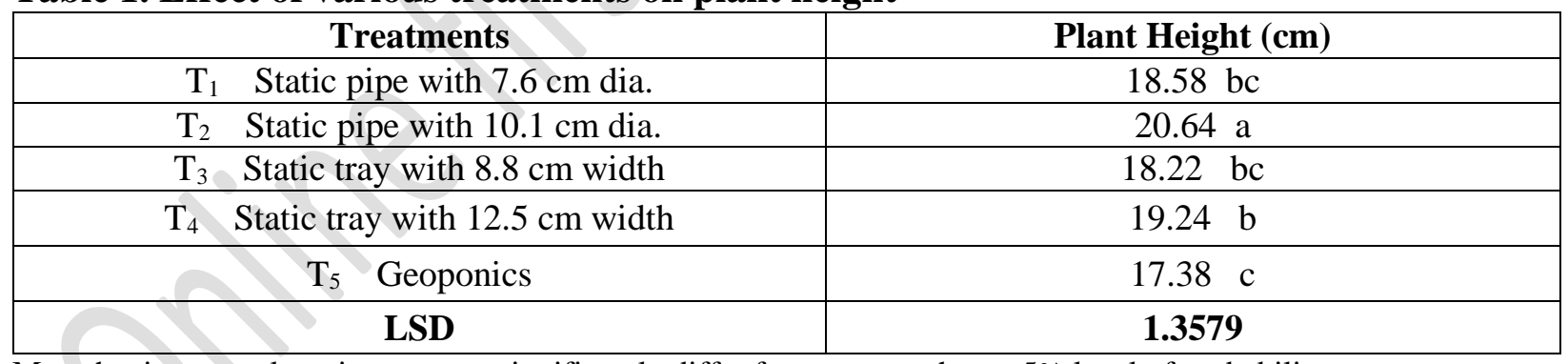

Mean having same lettering are non-significantly differ from one another at 5\% level of probability

\section{Number of leaves/plant (no.)}

Average number of leaves (Table 2) per plant in treatments $\mathrm{T}_{1}, \mathrm{~T}_{2}, \mathrm{~T}_{3}, \mathrm{~T}_{4}$ and $\mathrm{T}_{5}$ were observed 9.6, 10.8, 9.2, 10.2 and 8.4 respectively. Average number of leaves per plant in treatment $\mathrm{T}_{2}$ (10.8) were nonsignificantly differ with treatment $\mathrm{T}_{4}(10.2)$ and significantly different with all other treatments $\mathrm{T}_{1}(9.6), \mathrm{T}_{3}(9.2)$ and $\mathrm{T}_{5}(8.4)$ respectively at $5 \%$ level of probability. Average number of leaves in treatment $\mathrm{T}_{5}$ (8.4) geoponic is non-significantly different with $\mathrm{T}_{3}(9.2)$ and significantly differ with all other treatments $\mathrm{T}_{1}(9.6), \mathrm{T}_{2}(10.8)$ and $\mathrm{T}_{4}$ (10.2) at $5 \%$ level of probability. 
Number of leaves per plant is greater in static nutrient film technique than geoponics which is in accordance with the finding of scientist who stated that plants that are grown in soil have less number of leaves per plant than those plants grown in static nutrient film technique (open hydroponic system) [6].

Table 2. Effect of various treatments on number of leaves per plant

\begin{tabular}{|c|c|}
\hline Treatments & Number of Leaves per Plant \\
\hline $\mathrm{T}_{1} \quad$ Static pipe with $7.6 \mathrm{~cm}$ dia. & $9.6 \mathrm{~b}$ \\
\hline $\mathrm{T}_{2} \quad$ Static pipe with $10.1 \mathrm{~cm}$ dia. & $10.8 \mathrm{a}$ \\
\hline $\mathrm{T}_{3} \quad$ Static tray with $8.8 \mathrm{~cm}$ width & $9.2 \mathrm{bc}$ \\
\hline $\mathrm{T}_{4} \quad$ Static tray with $12.5 \mathrm{~cm}$ width & $10.2 \mathrm{ab}$ \\
\hline $\mathrm{T}_{5} \quad$ Geoponics & $8.4 \mathrm{c}$ \\
\hline LSD & 1.1349 \\
\hline
\end{tabular}

Mean having same lettering are non-significantly differ from one another at $5 \%$ level of probability

\section{Leaf length $(\mathrm{cm})$}

Leaf length (Table 3) of lettuce in all treatments of static hydroponic system and geoponics was measured. Leaf length in treatments $\mathrm{T}_{1}, \mathrm{~T}_{2}, \mathrm{~T}_{3}, \mathrm{~T}_{4}$ and $\mathrm{T}_{5}$ was observed 7.76, 8.64, 7.62, 7.96 and 7.50 respectively. Optimum leaf length (8.64) was recorded in treatment $\mathrm{T}_{2}$ while the lowest leaf length (7.50) was observed in treatment $T_{5}$. Leaf Length in treatment $\mathrm{T}_{2}(8.64)$ is significantly differ with its all competitors; treatments $\mathrm{T}_{1}$ (7.76), $\mathrm{T}_{3}$ (7.62), $\mathrm{T}_{4}$ (7.96) and $\mathrm{T}_{5}(7.50)$ respectively at $5 \%$ level of probability. Leaf length in treatment $\mathrm{T}_{5}(7.50)$ geoponic is nonsignificant with $\mathrm{T}_{1}(7.76), \mathrm{T}_{3}(7.62)$ and $\mathrm{T}_{4}$ (7.96) and significantly differ with all other treatments $\mathrm{T}_{2}(8.64)$ at $5 \%$ level of probability.

There is more leaf length is static nutrient film technique (open hydroponic) than geoponics which is in accordance with the finding of researcher who stated that there is more growth in hydroponic system than geoponics [7].

Table 3. Effect of various treatments on leaf length

\begin{tabular}{|c|c|}
\hline Treatments & Leaf Length (cm) \\
\hline $\mathrm{T}_{1} \quad$ Static pipe with $7.6 \mathrm{~cm}$ dia. & $7.76 \mathrm{~b}$ \\
\hline $\mathrm{T}_{2} \quad$ Static pipe with $10.1 \mathrm{~cm}$ dia. & $8.64 \mathrm{a}$ \\
\hline $\mathrm{T}_{3} \quad$ Static tray with $8.8 \mathrm{~cm}$ width & $7.62 \mathrm{~b}$ \\
\hline $\mathrm{T}_{4} \quad$ Static tray with $12.5 \mathrm{~cm}$ width & $7.96 \mathrm{~b}$ \\
\hline $\begin{array}{ll}\mathrm{T}_{5} & \text { Geoponics } \\
\end{array}$ & $7.50 \mathrm{~b}$ \\
\hline LSD & 0.4760 \\
\hline
\end{tabular}

Mean having same lettering are non-significantly differ from one another at $5 \%$ level of probability

\section{Leaf breadth $(\mathrm{cm})$}

Leaf breadth (Table 4) of lettuce was measured in all treatments of static hydroponic system and geoponics. Leaf breadth in treatment $\mathrm{T}_{1}, \mathrm{~T}_{2}, \mathrm{~T}_{3}, \mathrm{~T}_{4}$ and $\mathrm{T}_{5}$ was measured $4.38,4.88,4.20,4.60$ and $4.12 \mathrm{~cm}$ respectively. The greater leaf breadth (4.88) was observed in treatment $\mathrm{T}_{2}$ while the lowest leaf breadth (4.12) was observed in treatment $\mathrm{T}_{5}$. Leaf breadth in treatment $\mathrm{T}_{2}$ (4.88) is non-significantly differ with the treatments $\mathrm{T}_{1}$ (4.38) and $\mathrm{T}_{4}$ (4.60) respectively and significantly differ with treatments $\mathrm{T}_{3}(4.20)$ and $\mathrm{T}_{5}(4.12)$ at $5 \%$ level of probability. Leaf breadth in treatment $\mathrm{T}_{5}$ (4.12) geoponic is non-significantly differ with $\mathrm{T}_{1}$ (4.38), $\mathrm{T}_{3}$ (4.20) and $\mathrm{T}_{4}$ (4.60) respectively and significantly different with 
treatment $\mathrm{T}_{2}(4.88)$ at $5 \%$ level of probability.

There is more leaf breadth is static nutrient film technique (open hydroponic) than geoponics which is in accordance with the finding of researcher stated that there is more growth in hydroponic system than geoponics [6].

Table 4. Effect of various treatments on leaf breadth

\begin{tabular}{|cc|c|}
\hline Treatments & Leaf Breadth (cm) \\
\hline $\mathrm{T}_{1}$ & Static pipe with 7.6 cm dia. & $4.38 \mathrm{ab}$ \\
\hline $\mathrm{T}_{2}$ & Static pipe with $10.1 \mathrm{~cm}$ dia. & $4.88 \mathrm{a}$ \\
\hline $\mathrm{T}_{3} \quad$ Static tray with $8.8 \mathrm{~cm}$ width & $4.20 \mathrm{~b}$ \\
\hline $\mathrm{T}_{4} \quad$ Static tray with $12.5 \mathrm{~cm}$ width & $4.60 \mathrm{ab}$ \\
\hline \multicolumn{2}{|c|}{$\mathrm{T}_{5} \quad$ Geoponics } & $4.12 \mathrm{~b}$ \\
\hline LSD & $\mathbf{0 . 5 3 7 8}$ \\
\hline
\end{tabular}

Mean having same lettering are non-significantly differ from one another at 5\% level of probability

\section{Yield per plant (g)}

Yield per plant (Table 5) of lettuce was measured in all treatments of static hydroponic system and in geoponics at the end of cropping season. Yield per plant in treatments $\mathrm{T}_{1}, \mathrm{~T}_{2}, \mathrm{~T}_{3}, \mathrm{~T}_{4}, \mathrm{~T}_{5}, \mathrm{~T}_{5}$ was observed $190.80,245.80,176,213.40$ and 150.80 respectively. The greater yield per plant (245.80) was recorded in $T_{2}$ while the least yield per plant (150.80) observed in treatment $\mathrm{T}_{5}$. Yield in treatment $\mathrm{T}_{2}(245.80)$ is significantly differ with all other treatments $\mathrm{T}_{1}$ (190.80), $\mathrm{T}_{3}$ (176), $\mathrm{T}_{4}$ (213.40) and $\mathrm{T}_{5}$ (150.80) respectively at $5 \%$ level of probability. Yield per plant in treatment $T_{5}$ (150.80) geoponic is significantly differ with all other treatments $\mathrm{T}_{1}(190.80), \mathrm{T}_{2}(245.80)$, $\mathrm{T}_{3}$ (176) and $\mathrm{T}_{4}(213.40)$ at $5 \%$ level of probability.
There is more production of lettuce in static nutrient film technique than geoponics. Yield reduction in geoponic is due to positive and negative ions of silt and clay particles of soil. Nutrient react with these positive and negative ions of soil and forms chemical bonding, as result nutrients unavailable to plants and restrict proper growth. While in hydroponic all nutrient supplied were available to plant roots which is in accordance with the finding of scientists who studied that there is more production in static nutrient film technique (open hydroponic system) than geoponics [6, 7]. Another scientist also reported that is more production in hydroponic as compared with geoponics [9].

Table 5. Effect of various treatments on yield per plant

\begin{tabular}{|c|c|}
\hline $\begin{array}{c}\text { Treatments } \\
\end{array}$ & Yield per plant (g) \\
\hline $\mathrm{T}_{1}$ Static pipe with $7.6 \mathrm{~cm}$ dia. & $190.80 \mathrm{c}$ \\
\hline $\mathrm{T}_{2} \quad$ Static pipe with $10.1 \mathrm{~cm}$ dia. & $245.80 \mathrm{a}$ \\
\hline $\mathrm{T}_{3} \quad$ Static tray with $8.8 \mathrm{~cm}$ width & $176.00 \mathrm{~d}$ \\
\hline $\mathrm{T}_{4} \quad$ Static tray with $12.5 \mathrm{~cm}$ width & $213.40 \mathrm{~b}$ \\
\hline $\mathrm{T}_{5}$ Geoponics & $150.80 \mathrm{e}$ \\
\hline LSD & 7.0529 \\
\hline
\end{tabular}

Mean having same lettering are non-significantly differ from one another at $5 \%$ level of probability

\section{Conclusion and recommendations}

Highest mean yield $(245.8 \mathrm{~g})$ was recorded in treatment $\mathrm{T}_{2}$ in static pipe with $10.1 \mathrm{~cm}$ dia. while yield in equal volume of static tray with $12.5 \mathrm{~cm}$ width was observed $(213.4 \mathrm{~g})$. Average production in static pipe with $7.6 \mathrm{~cm}$ 
dia. was (190.8g) which is comparatively better than the equal volume of static galvanized steel tray $(176 \mathrm{~g})$ with $8.8 \mathrm{~cm}$ width. Minimum lettuce production was observed in geoponics (150.80g) as compared to static hydroponic system. For greenhouse lettuce production, it is therefore concluded that, circular shaped static hydroponic system was a better option as compared to geoponics. Research on automation of static nutrient film technique should be carried out to develop indigenously automation model for maintaining oxygen and nutrient EC and $\mathrm{pH}$. Consultancy services should be initiated by the Institute of Hydroponic Agriculture and Faculty of Agricultural Engineering for propagation of static nutrient film technique. The study is unique in the sense that it developed and introduced a new close hydroponic greenhouse lettuce production system. This is first such type of research work which have been done with significant research narrative for adoption strategies of close static nutrient film technique most feasible in protected environment with reuse of nutrient solution by maintaining its EC \& $\mathrm{pH}$.

\section{Authors' contributions}

Conducted experiment and wrote first draft of manuscript: A Qadeer, Supervised the experiment and helped in technical writing: ZU Haq, Technical guidance throughout the paper: SJ Butt, Corrected this manuscript: HM Asam \& MK Nawaz, Formatted the manuscript and helped statistical analysis: T Mehmood, Helped in data collection: SR Haidree.

\section{Acknowledgments}

I am highly thankful to Dean, Faculty of Agricultural Engineering \& Technology and Director, Institute of Hydroponic Agriculture for providing me facilities and infrastructure required during this research.

\section{References}

1. Sharma A, Kumar S \& Chaurasia (2018). Hydroponics as an advanced technique for vegetable production: An overview. J Soil Water Conserv 17(4): 364-371.

2. Kruchkin A (2013). Hydroponic crop farming. IBISWorld Industry Report OD4012. Retrieved March 9, 2013.

3. Butt SJ \& Varis S (1999). Production of lettuce in different growing media in cold glasshouse (in Turkish). HASAD, Istanbul 14: 32-35.

4. Kratky BA (2015). Growing direct-seeded watercress by two non-circulating hydroponic methods.

5. Kaiser C \& Ernst M (2016). Hydroponic lettuce. CCD- CP-63. Lexington, KY: Center for Crop Diversification, University of Kentucky College of Agriculture, Food and Environment.

6. Alshrouf A (2017). Hydroponics, aeroponic and aquaponic as compared with conventional farming. Amer Sci Res J Engg Tech Sci 27(1): 247-255.

7. Barbosa GL, Daiane F, Gadelha A, Kublik N, Proctor A, Reichelm L \& Halden RU (2015). Comparison of land, water, and energy requirements of lettuce grown using hydroponic vs conventional agricultural methods. Intl J Envir Res Pub H 12: 6879-6891.

8. Singh H \& Bruce D (2016). Electrial conductivity and $\mathrm{Ph}$ guide for hydroponics. Oklahoma State University, Division of Agricultural Sciences and Natural Resources pp 5.

9. Goenka A (2018). Hydroponics v/s geoponics. Intl J Emerg Res Dev 1(5): 4144. 